\title{
Interdisciplinary perspectives on grandparental investment: a journey towards causality
}

\section{David A. Coall, Sonja Hilbrand, Rebecca Sear \& Ralph Hertwig}

To cite this article: David A. Coall, Sonja Hilbrand, Rebecca Sear \& Ralph Hertwig (2018) Interdisciplinary perspectives on grandparental investment: a journey towards causality, Contemporary Social Science, 13:2, 159-174, DOI: 10.1080/21582041.2018.1433317

To link to this article: https://doi.org/10.1080/21582041.2018.1433317
(c) 2018 The Author(s). Published by Informa UK Limited, trading as Taylor \& Francis Group

Published online: 09 Feb 2018.

Submit your article to this journal $\widetilde{ }$

Џلll Article views: 206

Q View related articles ๘

$\bigoplus_{\text {CrossMark }}$ View Crossmark data \lceil

4 Citing articles: 1 View citing articles 


\title{
Interdisciplinary perspectives on grandparental investment: a journey towards causality
}

\author{
David A. Coall ${ }^{a, b}$, Sonja Hilbrand ${ }^{c, d}$, Rebecca Sear ${ }^{\mathrm{e}}$ and Ralph Hertwig ${ }^{\mathrm{d}}$ \\ ${ }^{\mathrm{a} S}$ School of Medical and Health Sciences, Edith Cowan University, Joondalup, WA, Australia; ${ }^{\mathrm{b}}$ Division of \\ Psychiatry, School of Medicine, University of Western Australia, Crawley, WA, Australia; 'Department of \\ Psychology, University of Basel, Basel, Switzerland; ${ }^{d}$ Center for Adaptive Rationality, Max Planck Institute for

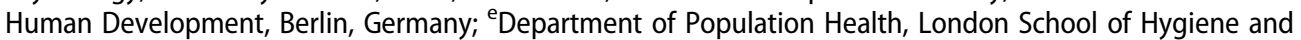 \\ Tropical Medicine, London, UK
}

\section{ABSTRACT}

Why do grandparents invest so heavily in their grandchildren and what impact does this investment have on families? A multitude of factors influence the roles grandparents play in their families. Here, we present an interdisciplinary perspective of grandparenting incorporating theory and research from evolutionary biology, sociology and economics. Discriminative grandparental solicitude, biological relatedness and the impact of resource availability are three phenomena used to illustrate how these perspectives, within such a multi-level approach, add value by complementing not competing with each other. Changing demographics mean there is greater demand and opportunity for actively engaged grandparents to help their families, especially in times of need. Grandparents have been filling this emerging niche because in some societies the role of community and government never has, or increasingly cannot, meet the diverse needs of families. Built on an empirical foundation of descriptive and correlational research, grandparent research has rapidly entered a phase where the potential causal relationships between grandparents' roles and family health, well-being and structure can be scrutinised. Together, these investigations are producing high-quality evidence that ultimately can support informed public policy and service delivery decisions. We finish by detailing two examples of such research efforts that highlight opportunities for future research.

\section{ARTICLE HISTORY}

Received 15 November 2017

Accepted 23 January 2018

\section{KEYWORDS}

Grandparents;

interdisciplinary perspectives; grandparent health; grandparental investment; grandchild development

\section{Introduction}

The cooperative breeding nature of human societies means that grandparents are likely to have contributed substantial amounts of time, knowledge, guidance, money and care to their families and communities throughout human history (Hrdy, 2009). At the same time, however, systematic differences between grandparents will influence grandparents' involvement, the role they play and the consequences their behaviour exacts. Such differences concern timing of marriage, family formation, health and life expectancy, financial, emotional and social resources, life experiences and socialisation (Szinovacz, 1998a; 
Tran, Fisher \& Voracek, 2009). Despite a range of demographic changes prompting an often predicted decline in the role of grandparents under the dominance of the nuclear family in industrialised societies, grandparents' roles in families were, have been and will remain crucial (Bengtson, 2001). Recent reviews highlight the myriad roles grandparents are managing and the challenges they throw-up: grandparents providing childcare in the face of reduced institutionalised childcare support, the increased intensity (frequency and duration) of childcare, grandfathers' changing roles, conflicts with working, retirement, personal interests and caring for elderly parents, three-generation households, children with disability and custodial grandparents (Buchanan \& Rotkirch, 2016; Coall \& Hertwig, 2010; Harrington Meyer \& Abdul-Malak, 2016; Taylor, Marquis, Batten, \& Coall, 2016). These issues, among many, are fuelling a burgeoning field of grandparent research.

Across disciplines, we are taught correlation (the association between two variables) is not causation (change in one variable causing a change in another). In biology and medicine, the random allocation of individuals to experimental groups is the gold standard in establishing causality. At the same time, for many aspects of human behaviour such interventions are not ethical or practical. In grandparental research, correlational evidence is crucial in building our understanding of causal pathways. However, we do need to move beyond correlational research in order to fully understand causal mechanisms (see Ates, 2017; Hayslip, Fruhauf, \& Dolbin-MacNab, 2017; Laland, Sterelny, Odling-Smee, Hoppitt, \& Uller, 2011; Rutter, 2009). These causal pathways can be explored through path analysis and structural equation modelling as well as methods that address issues of reverse causality (e.g. lagged dependent variables) and singling out individual change over time (e.g. within-individual fixed-effect models). Finally, natural experiments and targeted interventions can also contribute to understanding causality. In conjunction, these diverse methods foster our understanding of correlations observed in grandparent research and permit informed inference to potential causal relationships.

In biology, a distinction is also made between causes operating at different levels: Proximate causes examine the mechanistic or functional levels of physiology and psychology while ultimate causes operate at a historical or evolutionary level explaining why a trait or characteristic exists (Mayr, 1961). We will use this perspective to show how disciplines complement each other by exploring different but by no means mutually exclusive levels of explanation, usefully building our understanding of grandparental investment.

Here, we present an interdisciplinary framework by bringing together theory and research from evolutionary biology, sociology and economics to examine why grandparents care. We then explore the involvement of different types of grandparents, the role of biological relatedness and the impact of resource availability as phenomena that exemplify the complementary nature of these disciplines. Finally, we provide two research examples focused on scrutinising the potential causal relationships between grandparents' childcare and its consequences for grandparents' health and the impact it may have on family structure, specifically fertility. These examples highlight opportunities for future research.

\section{Why do grandparents care?}

While the arrival of a grandchild is often accompanied by excitement and an immediate connection (St George \& Fletcher, 2014), there are myriad dimensions that influence 
the subsequent role and impact grandparents have within families. Substantial progress towards understanding these dimensions has been made by disciplines as diverse as sociology, economics and evolutionary biology (Coall \& Hertwig, 2010), but to date, each discipline has worked largely in isolation (Coall \& Hertwig, 2011). In addition, each discipline answers the question of why grandparents care differently. We have argued (Coall \& Hertwig, 2010) that to achieve the greatest impact in this research area, it is time to join forces, by simultaneously exploring grandparental investment on multiple levels.

\section{The evolutionary perspective}

The broadest level of explanation highlights humans within an evolutionary context as cooperative breeders. According to the cooperative breeding hypothesis, a mother does not raise her children by herself but is helped by other members of her social group (Hrdy, 2009). In both traditional societies (generally low income, higher fertility, higher mortality with limited access to medical services) and contemporary industrialised or post-industrial societies (generally high income, low fertility, low mortality, access to medical services), these helpers are not necessarily kin (Coall, Hilbrand, \& Hertwig, 2014; Ivey, 2000). Yet, one class of kin helper that has persisted throughout history, and has been inclined to help, is that of the post-reproductive adults grandparents.

Within this predominantly anthropological literature, Williams' (1957) suggestion that menopause in humans was unique among animal species focused research on the role of grandmothers. This thesis triggered numerous investigations into the influences of grandmothers, and other kin, on the survival of offspring, and has culminated in the grandmother hypothesis (and its variants: see Coall \& Hertwig, 2010). The grandmother hypothesis proposes that grandmothers are the most knowledgeable, efficient and motivated kin for women to help raise their grandchildren and enhance their own inclusive fitness by improving the reproductive success of their children (Hawkes, O'Connell, \& Blurton Jones, 1997; Hawkes, O'Connell, Blurton Jones, Alvarez, \& Charnov, 1998; Sear \& Coall, 2011). Thus grandparenting, especially grandmothering, is seen as conferring a selective advantage that drives human longevity and ultimately extends the human life cycle for both males and females (Kim, McQueen, Coxworth, \& Hawkes, 2014).

In their now classic investigation exploring the influence family members have on child survival, Sear and Mace (2008) reviewed 45 studies investigating this issue. Their findings generally, but not universally, support the beneficial influence of post-reproductive relatives, especially the maternal grandmother, in high fertility societies: $69 \%$ (9 of 13) studies found that the presence of a maternal grandmother was associated with increased grandchild survival. Paternal grandmothers are less consistently associated with positive child outcomes: her presence had a positive association in $53 \%$ of studies, but a negative association in $12 \%$ and none in $35 \%$.

There is less evidence that caring by grandfathers provides an adaptive explanation for why grandparents exist. Sear and Mace (2008) found in only 2 of 12 studies, and 3 of 12 studies, that the presence of maternal or paternal grandfathers (respectively) was positively associated with child survival. Furthermore, no evidence was found that 
grandfathers who lived longer ultimately had more grandchildren in a historical Finnish population (see Lahdenperä, Lummaa, \& Russell, 2011). This is perhaps because, although men can continue to repartner and father children until relatively late in life (Lahdenperä, Russell, \& Lummaa, 2007), repartnering seems to involve channelling of resources to a new family and away from their previous family. Such reductions of paternal investment are seen not just in this historical population (Lahdenperä et al., 2011) but also in serially remarried families in industrialised nations (Tanskanen, Danielsbacka, \& Rotkirch, 2014). These first findings provide little reason to assume that grandfathering would have been favoured by natural selection because it benefitted survival or reproduction. It can, however, have emerged as a by-product of selection for female longevity (Hrdy, 1999). This research, however, is still in its infancy, and does not preclude benefits of grandfathering at the family and individual level.

\section{The economic perspective}

Intergenerational transfers can take many forms: inheritance and financial or time transfers. Transfers can be upward or downward. Possibly because of this variety, there is no overarching economic model of parental, let alone grandparental, investment. Nevertheless, most models rest on the utility maximisation and rational choice framework, and many models of intergenerational transfers between family members have proposed the existence of two competing motives: altruism and self-interested exchange.

According to the first motive (see Becker, 1974 and Barro, 1974), a parent's welfare is partly a function of the welfare of their children and grandchildren. Specifically, the parent's utility function incorporates the child's likely lifetime utility. This would explain why parents shift resources to their children as a function of those children's quality (e.g. skills and abilities) and later use wealth transfers to equalise outcomes across children (redistributive neutrality). Successive generations are thus linked by recursive altruistic preferences. That is, parents care altruistically for their children, who then transfer resources to their children, and so on. In the self-interested exchange view, parents' transfers are part of a strategic bargaining between parents and children (see Laferrère \& Wolff, 2006). Intergenerational transfers can be understood as an investment through which parents try to secure their children's commitment in the future. Anticipating that when they become frail they will need help, parents invest now (e.g. education expenses, gifts and loans) and in the future (promise of inheritance) to increase the likelihood that their children will help them in the time of need.

There are a number of empirical challenges to both the altruistic and the self-interested exchange views (see Arrondel \& Masson, 2006). One problem for the altruistic view, for example, is that parents transfer most of their wealth through bequests, rather than earlier in the form of gifts, when children need them most. The self-interested exchange view faces the problem that although grandparents undoubtedly do invest substantial amounts of resources in their grandchildren, there is little evidence that grandchildren consistently reciprocate. Despite these challenges, the economic perspective focuses attention on the proximate, economic and instrumental reasons why parents and grandparents may invest in their descendants, which has broad implications across disciplines. 


\section{The sociological perspective}

Within the sociological modernisation paradigm, the extended family first received scant attention as the emphasis rested on the nuclear family. In recent decades, demographic dynamics and the increasing fragility of state-funded pension schemes, however, have pushed the issues of intergenerational exchanges and intergenerational solidarity to centre stage. In studying these issues, sociologists have been predominately focused on structural factors (e.g. female participation in the labour force), social institutions (e.g. how wealth is taxed at death), cultural values (e.g. family obligations and roles) and intergenerational relationships (between grandparents, parents and children). Their investigations have produced a wealth of information on factors that clearly have consequences for patterns of grandparental investment but are consistently neglected by other fields (e.g. individual values and cultural norms). Now, by far the majority of research examining the roles of grandparents has been conducted within sociology. A factor acknowledged by sociologists, limiting the potential value of this research, is the lack of an overarching theoretical framework (Szinovacz, 1998b).

One attempt towards creating an encompassing framework is the rational-grandparent model (Friedman, Hechter, \& Kreager, 2008). Echoing the self-interested exchange view in economics, this model assumes that the driving force behind investments is grandparents' concern about how they will be provided for in old age. To reduce this uncertainty, grandparents preferentially invest in those grandchildren whose parents are most likely to reciprocate in the future. Moreover, despite a tacit and widespread norm in modern societies to invest in children and grandchildren equally (Hertwig, Davis, \& Sulloway, 2002), this utility perspective promotes favouritism, which, surprisingly, is consistently found in self-report measures (Suitor, Sechrist, Plikuhn, Pardo, \& Pillemer, 2008). Informatively for the current interdisciplinary perspective on grandparents, favouritism of children by parents, whether intentional or not, varies by family stress (e.g. divorce), family structure (e.g. birth order), biological relatedness, birth order, behaviour and personality (Hertwig et al., 2002; Suitor et al., 2008). Although the rational-grandparent model ignores important issues (e.g. need and biological relatedness), it offers testable predictions about how grandparental investment varies.

\section{Why maternal grandmothers care most: complementary explanations of a robust pattern}

Treating all grandparents, or even all grandmothers and grandfathers, as homogeneous groups is remiss. It neglects the enormous variability among grandparents and the circumstances under which they contribute to their families. Across disciplines and measures of grandparental care, solidarity, transfers, support and closeness, the most robust pattern found in industrialised nations is in all likelihood that maternal grandmothers tend to invest the most in their grandchildren, followed by maternal grandfathers, then paternal grandmothers, with paternal grandfathers investing the least (see Dubas, 2001; Eisenberg, 1988; Euler \& Weitzel, 1996; Pollet, Nelissen, \& Nettle, 2009; Uhlenberg \& Hammill, 1998). Across disciplines, however, quite different explanations for this pattern exist.

At the proximate level of explanation, sociological theorising holds that women are kinkeepers, tasked with holding kin groups together (Dubas, 2001; Eisenberg, 1988). Similarly, 
according to the sociological family systems theory, it is the gatekeeper role of the parent (middle) generation that encourages (or not) the grandparent-grandchild relationship (Chan \& Elder, 2000; Rossi \& Rossi, 1990). Consequently, when grandparent and parent are female (e.g. maternal grandmother), the bond between grandparent and grandchild will be stronger relative to both parties being male (e.g. paternal grandfather).

At the ultimate level, evolutionary perspectives attribute this association between grandparent type and involvement (discriminative grandparental solicitude; Euler \& Weitzel, 1996) to sex-specific reproductive strategies and paternity uncertainty (see Table 1 in Coall \& Hertwig, 2010). Purely because grandparents are related to their grandchildren, evolutionary theory does not predict they will invariably help their grandchildren. Rather, according to Hamilton's rule (Hamilton, 1964), helping is moderated by opportunity costs that may differ across types of grandparents (e.g. grandmother vs. grandfather) making some investment alternatives more valuable than others.

Theoretically, paternity uncertainty is also predicted to play a role, albeit not necessarily consciously. Whereas women are certain who their children are, males do not know with certainty that they are the biological fathers of their putative children. Grandparents with higher levels of certainty of their biological relationship to their grandchildren are assumed to invest more. This assumption can explain why maternal grandmothers, certain of their relationships with their daughters and their daughters' relationship with their grandchildren, invest more than paternal grandfathers (see Smith, 1987). The fact that these patterns of grandparental investment may be confined to industrialised societies and are not always present in rural (Kaptijn, Thomese, Liefbroer, \& Silverstein, 2013; Pashos, 2000) and more traditional populations (Snopkowski \& Sear, 2015) means there is some question about the actual impact of paternity uncertainty alone (Perry \& Daly, 2017), perhaps because paternity uncertainty varies between populations (Anderson, 2006; Sear, 2016). The recognition that paternity uncertainty is typically low in human populations (Anderson, 2006) has led to the recent development of additional evolutionary arguments to explain grandmaternal bias: it may be that care allocated to the mother will translate into greater fitness benefits for the maternal kin because it enhances the reproductive success of both mother and child, whereas paternal kin only gain fitness benefits through the child (Perry \& Daly, 2017).

To conclude, the strength of a genuine interdisciplinary perspective is patent following the contribution of these disciplines to our understanding of grandparents. Some progress and perspective has been limited in the past due to the isolation of these disciplinary approaches to grandparental investment (see Coall \& Hertwig, 2011). Similar and broadly compatible predictions (Dubas, 2001; Huber \& Breedlove, 2007), similar research methodologies (Euler \& Weitzel, 1996; Mangen, Bengtson, \& Landry, 1988), but with a focus on different levels of explanation (i.e. the mechanistic, proximate explanations of economics, sociology and psychology vs. the adaptationist, ultimate explanations of evolutionary biology), mean these disciplines are complementary, together building a comprehensive framework of grandparental behaviour and care.

\section{Complementary views on biological relatedness}

Perhaps, the key variable considered in the evolutionary grandparental investment literature is biological relatedness, which has resulted in calls to introduce genetic relatedness 
into interdisciplinary studies (Kaptijn et al., 2013). As predicted in this literature, evidence is emerging that the genetic relationship between grandparents and grandchildren is an independent predictor of intense grandparental investment, even in contemporary European societies. Using the Survey of Heath Ageing and Retirement across Europe, Coall et al. (2014) found that while biological grandparents were more likely to provide frequent informal childcare for their grandchildren, non-biological grandparents, who are typically step-grandparents, still invested in their grandchildren and were more likely to invest on a monthly basis or less frequently (see also Gray \& Brogdon, 2017). Such intensive, quality investment between grandchildren and their biological grandparents across nuclear, step-parent and single-parent families have been associated with improved emotional health of grandchildren (Ruiz \& Silverstein, 2007). The impact of biological relatedness, however, is often seen as incompatible with sociological and economic models of parental and grandparental investment. These models often assume investment to flow to those grandchildren (and their parents) who are more likely to reciprocate in times of need.

But reciprocal altruism, often conceptualised as exchanges between unrelated individuals, is likely to have originally evolved in genetically related kin groups and generalised subsequently (Hilbrand, Coall, Gerstorf, \& Hertwig, 2017). The psychological traits that maintain a system of reciprocity in humans (e.g. guilt, trust, sympathy and gratitude) (Trivers, 1971) are likely to be stronger between close kin (but see Rotkirch, Lyons, David-Barrett, \& Jokela, 2014). This, in turn, promotes close kin as less risky partners with whom to reciprocate (Allen-Arave, Gurven, \& Hill, 2008).

A strong attachment between parent and child has been proposed as a proximate mechanism for parents to identify and favour caring for their biological children (Daly \& Wilson, 1980). A similarly strong attachment relationship may also be found when parents adopt a young child (Hrdy, 2009). Quality grandparent-grandchild attachment relationships may provide a crucial proximate mechanism whereby grandparents identify and preferentially care for grandchildren of their own children (Euler \& Weitzel, 1996; Kennedy, 1990). Indeed, the many non-biological grandparents who do invest in stepgrandchildren may do so because of particularly harmonious relationships between family members. Conversely, in some cases biological grandparents may not invest due to poor intergenerational relationships (Coall et al., 2014). Grandparents may also be investing in non-biological grandchildren as part of establishing and maintaining a new relationship to the new partners of their children (i.e. mating effort in biology; Anderson, Kaplan, \& Lancaster, 1999; Gray \& Brogdon, 2017; Pashos, Schwarz, \& Björklund, 2016). However, on balance, it is likely that investment in biological grandchildren improves inclusive fitness and is simultaneously more likely to be reciprocated. Consequently, the finding that high levels of investment are more likely to come from biological grandparents can, in principle, be reconciled with economic, psychological or sociological accounts of grandparental investment.

\section{Resources matter: family size, birth order and kin networks}

So far, we have discussed grandparental discriminative solicitude and biological relatedness as predictors of grandparental investment. In addition, the availability of resources is likely to influence investment and, yet, they are not routinely included in most analyses. Variation in grandparental resource availability is partly a function of family type and size. 
The preponderance of the nuclear family in industrialised nations means concomitant changes in family size, birth order and availability of other kin. In traditional societies, larger families can recruit older siblings to provide resources for a family (Ivey, 2000; Kramer, 2002). In industrialised societies, in contrast, the impact of sibling help for child care is likely to be low because siblings are few, closely spaced and contribute little to the family economy (Sear \& Coall, 2011). In both cases, a larger family size, ceteris paribus, dilutes the resources available for each child (Blake, 1987; Hertwig et al., 2002; Marks, 2006) and grandchild (Coall, Meier, Hertwig, Wänke, \& Höpflinger, 2009; Uhlenberg \& Hammill, 1998).

Resources available to the parental generation are also likely to influence grandparental investment, and the evidence that grandparents have a larger influence on their children during times of need has been established (Coall \& Hertwig, 2010). However, the question of whether grandparents intentionally direct their resources where the need is greatest has received less attention. Need is an important new variable that is emerging in the grandparental investment literature (Roberto, Allen \& Blieszner, 2001; Snopkowski \& Sear, 2015; Szydlik, 2008; Thomese \& Liefbroer, 2013). It is also a variable that is not entirely dealt with by the predominant, utility-based models detailed above and is likely to benefit from consideration of evolutionary perspectives (Hooper, Gurven, Winking, \& Kaplan, 2015). Need and responding to need is likely to be important in single-parent families and step-families that are often resource poor, especially in terms of social capital (see Sear \& Coall, 2011).

The low-resource environments often found in single teenage mother families provide a new niche where help from grandparents, specifically grandfathers, may be particularly beneficial (see Coall, Hilbrand, Sear, \& Hertwig, 2016; Schaffnit \& Sear, 2017). Evidence is emerging from studies, explicitly focusing on single-parent families (e.g. in the US), that a resident grandfather can have a significant influence on grandchild development: improving child behaviour and affect (e.g. Oyserman, Radin, \& Benn, 1993). Potentially, this role may be an emerging contemporary niche for grandfathers. Next, we present two research examples where attempts to understand the causal dynamics of grandparents' roles are proving fruitful.

\section{Interdisciplinary perspectives: building the bridge between correlation and causation}

Like many other fields of research, the investigation of grandparenting will eventually have to answer one key question: To what extent do the common correlations reflect causal dynamics? Methodological issues pertinent to grandparent research are being discussed across disciplines (e.g. Ates, 2017; Hayslip et al., 2017; Michalski, 2010). Over recent decades, a substantial body of descriptive and correlational grandparent literature has been accumulated. As correlation is a necessary but not sufficient condition of a causal relationship, this correlational literature is valuable and helps to search for and explore causal relationships (see Laland et al., 2011). Moreover, correlational evidence will continue to be valuable as we explore any new question or variable. However, correlations between the presence of grandparents and grandchild outcomes, for example, may be confounded by shared genes or environment. In addition, further work is needed to explore the extent to which associations may vary by SES (moderation) and how such associations are 
mediated (e.g. through the childcare grandparents provide; Baron \& Kenny, 1986). We believe that these issues will be gradually resolved through a plurality of methods: from the use of more targeted, experimental or intervention study designs at the one end and the application of statistical models to longitudinal data to understand changes within individuals over time at the other end. These models exploring both betweenand within-individual variation have been used for some time (Silverstein \& Long, 1998). Here, we provide two examples where longitudinal data are being used to corroborate, or not, the correlational evidence and evidence from cross-sectional studies.

\section{Is grandchild care good for grandparental health and longevity?}

From an evolutionary perspective, it has been hypothesised that helping behaviour within and beyond the family ultimately developed from ancestral parenting and grandparenting (Chisholm, 2017; Chisholm, Coall, \& Atkinson, 2016; Hrdy, 2009; Kurzban, Burton-Chellew, \& West, 2015) and has potentially contributed to extending the human lifespan (Kim et al., 2014). It is possible that echoes of this distant selective pressure can still be seen at the proximately level in contemporary human populations. Recent evidence suggests that among elderly people, helpful grandparents, parents and unrelated community members experience increased survivorship compared to individuals who do not help (Hilbrand, Coall, Gerstorf, et al., 2017). Using data from the 516 participants in the Berlin Ageing Study, Hilbrand, Coall, Gerstorf, et al. (2017) found that helpful grandparents who looked after their grandchildren survived 5 years longer than non-caregiving grandparents or non-grandparents. Positive associations between grandparental childcare assistance and grandparental health (mortality not tested here) have also been found in multiple waves of the Survey of Health Ageing and Retirement in Europe (SHARE; Di Gessa, Glaser, \& Tinker, 2016a, 2016b).

One obvious potential mechanism linking active grandparenting (e.g. grandparental childcare) and reduced mortality is that grandparenting improves a grandparent's health and well-being, which in turn reduces mortality. In a mediation analysis using structural equation modelling, grandparenting and supporting others were associated with improved subsequent health, which was in turn associated with longevity. Subsequent health partially mediated the associations between grandparenting and supporting others and longevity, accounting for $22 \%$ of this relationship (Hilbrand, Coall, Meyer, Gerstorf, \& Hertwig, 2017). Therefore, health is likely to be on this causal path; however, more detailed information exploring issues of motivation, emotion and relationship quality are required to fully understand the mechanisms involved.

In an attempt to move a step closer to the causal association between grandchild care and grandparents' health, Ates (2017) used a longitudinal fixed effects model to examine data from the German Aging Survey. These models help look at the change in individuals over time (within-individual differences), thus removing the impact of unmeasured differences that can confound cross-sectional studies (between-individual differences). Three waves of data, from 2008, 2011 and 2014, were examined across 625 participants. The analysis showed that a change in the amount of grandchild care by grandparents did not influence their subsequent self-rated health (note that in Hilbrand, Coall, Meyer, et al., 2017, grandparents' prospective health was measured using predominantly objective indicators). 
An initial analysis of five waves of the longitudinal SHARE suggests, however, that specific aspects of grandparental health, particularly physical health, may benefit from grandchild care (Danielsbacka, Tanskanen, Coall, \& Jokela, 2017). Similar to Ates (2017), a between- and within-individual analysis was conducted on 24,787 people aged 50 and above, across 11 countries, over four follow-up waves between 2004 and 2015. Across all analyses, grandparental childcare was associated with increased self-rated health, fewer difficulties with activities of daily living and depressive symptoms, increased life satisfaction and meaning of life scores. These associations held for between-person differences: on average grandparents who looked after their grandchildren subsequently reported better health. In the within-individual analysis, however, the only association that remained significant showed that the number of difficulties with activities of daily living decreased over time among grandparents whose childcare frequencies had increased previously. In line with previous longitudinal evidence associating babysitting with improved health (Hilbrand, Coall, Meyer, et al., 2017) and increased exercise (Hughes, Waite, LaPierre, \& Luo, 2007), these findings are consistent with the association between grandchild care and grandparental well-being working specifically through physical health. Clearly, the final word on this association is some time away. Improved measures that examine grandparental involvement beyond grandchild care will help our understanding of potential mediating pathways.

\section{Grandparenting and their children's fertility}

From an evolutionary perspective, the grandmother hypothesis proposes that by providing guidance, practical help and childcare, post-reproductive women aided the survival and reproduction of their children (Hawkes et al., 1997, 1998). Similarly, from sociological and macro-economic perspectives, even in high income contexts, grandparental childcare reduces both the financial and time costs of parental care that enables subsequent fertility and labour force participation for woman (Coall \& Hertwig, 2010; Hank \& Buber, 2009; Hank \& Kreyenfeld, 2003; Kanji, 2017; Pronzato, 2017; Sear \& Coall, 2011). Bringing these perspectives together, in a cross-cultural study of more than two million married women, Huber, Zahourek, and Fieder (2017) found that co-residence with a mother's mother or mother in-law was associated with earlier reproductive debut but ultimately reduced fertility. This was most readily interpreted as local resource competition where competition among family members reduces resource availability (see Strassmann \& Garrard, 2011).

Nevertheless, the question remains: does what grandparents do influence subsequent fertility? Using the longitudinal Indonesian Family Life Survey, which has data on both grandparental availability and actual helping behaviour (in terms of financial resources and domestic help) between the grandparental and parental generations, Snopkowski and Sear (2016) used causal mediation analysis to answer this question. They show that the positive association between grandparental availability and their children's fertility is mediated by the actual provision of help from grandparents - that is, mere kin availability does not suffice but produces a positive association with fertility only when kin actually provide help. Again this finding highlights the importance of proximate mechanisms and understanding what grandparents actually do to fully understand the impact their presence, contact or childcare has. 


\section{Conclusion: a journey towards causation}

In a range of areas, the grandparental investment research literature has developed to a point where longitudinal data from observational studies are being used to examine the change in individuals over time. This information usefully adds to understanding these relationships. However, their continued success relies on the clarity of explanation not the technical prowess: Policy-makers, service providers and the public need to be able to utilise this information to improve lives. A remaining challenge is that these longitudinal studies have typically not been designed to specifically examine questions related to grandparents and grandchildren, limiting their scope and impact. Rarely does a study systematically observe or record the remarkable variation in actual behaviours across generations to demonstrate how much (or not) grandparents help and families are helped (see Coall et al., 2009; Gibson \& Mace, 2005; Pittman 2007; Tinsley \& Parke, 1987). As this research continues to gather pace, investment may be made in designing controlled intervention studies as the next step towards examining causality within these complex relationships. Clinical trials of existing human services and specific interventions aimed at grandparents that impact their roles in families will contribute to the mechanistic evidence base (e.g. Smith, Strieder, Greenberg, Hayslip, \& Montoro-Rodriguez, 2016). This rapidly expanding field of research is producing evidence that ultimately supports informed public policy and service delivery decisions. Perhaps most importantly, this recent focus on explicitly examining causal relationships reminds us to be cognisant of our implicitly held causal assumptions and the need to produce ever more precise theories thereof and exacting methods to investigate them.

\section{Disclosure statement}

No potential conflict of interest was reported by the authors.

\section{Funding}

This work was supported by European Research Council [Grant Number 263760] and Lotterywest [Grant Number 421009223].

\section{Notes on contributors}

David A. Coall is a Senior Lecturer in the School of Medical and Health Sciences at Edith Cowan University in Perth, Western Australia. He is an interdisciplinary researcher who explores intergenerational influences on development, health and behaviour within families. Of particular interest are the different roles grandparents play and how they impact family functioning, grandchild development and the health of the grandparents themselves. His work is now being translated into support services for families in low resource availability situations.

Sonja Hilbrand is a psychotherapist and a researcher at the Department of Psychology at the University of Basel, Switzerland. She has written on human helping behaviour and is interested in how grandparenting impacts families on multiple levels, in particular grandparental health. Her research combines approaches from evolutionary theory, psychology, and sociology. In her practical work Hilbrand translates scientific knowledge into creative interventions in order to help her clients and their families to achieve better and lasting health. 
Rebecca Sear is a demographer and anthropologist at the London School of Hygiene and Tropical Medicine. Much of her research has focused on the family, and how the extended family influences demographic and health outcomes. She is also interested in interdisciplinary research, in particular bringing evolutionary theory into the social sciences and public health.

Ralph Hertwig is Director of the Center for Adaptive Rationality at the Max Planck of Human Development in Berlin, Germany. His has published extensively on how humans make decisions especially with the help of simple boundedly rational models and learning processes under the conditions of time pressure, lack of information and uncertainty. He also examines how people can be helped to make better decisions and is particularly interested in how to make decision makers competent through cognitive and motivational boosts.

\section{References}

Allen-Arave, W., Gurven, M., \& Hill, K. (2008). Reciprocal altruism, not kin selection, maintains nepotistic food transfers on an Ache reservation. Evolution and Human Behavior, 29, 305-318.

Anderson, K. G. (2006). How well does paternity confidence match actual paternity? Evidence from worldwide nonpaternity rates. Current Anthropology, 48, 511-518.

Anderson, K. G., Kaplan, H., \& Lancaster, J. (1999). Paternal care by genetic fathers and stepfathers I. Evolution and Human Behavior, 20, 405-431.

Arrondel, L., \& Masson, A. (2006). Altruism, exchange or indirect reciprocity: What do the data on family transfers show? In S. C. Kolm \& J. M. Ythier (Eds.), Handbook of the economics of giving, altruism and reciprocity (Vol. 2, pp. 971-1053). Amsterdam: Elsevier.

Ates, M. (2017). Does grandchild care influence grandparents' self-rated health? Evidence from a fixed effects approach. Social Science and Medicine, 190, 67-74.

Baron, R. M., \& Kenny, D. A. (1986). The moderator-mediator variable distinction in social psychological research: Conceptual, strategic, and statistical considerations. Journal of Personality and Social Psychology, 51, 1173-1182.

Barro, R. J. (1974). Are government bonds net wealth? Journal of Political Economy, 82, 1095-1117.

Becker, G. S. (1974). A theory of social interactions. Journal of Political Economy, 82, 1063-1093.

Bengtson, V. L. (2001). Beyond the nuclear family: The increasing importance of multigenerational bonds. Journal of Marriage and Family, 63, 1-16.

Blake, J. (1987). Differential parental investment: Its effects on child quality and status attainment. In J. B. Lancaster, J. Altmann, A. S. Rossi, \& L. R. Sherrod (Eds.), Parenting across the life span: Biosocial dimensions (pp. 351-375). New York, NY: Aldine de Gruyter.

Buchanan, A., \& Rotkirch, A. (Eds.). (2016). Grandfathers: Global perspectives. London: Palgrave Macmillan.

Chan, C. G., \& Elder, G. H. (2000). Matrilineal advantage in grandchild-grandparent relations. The Gerontologist, 40, 179-190.

Chisholm, J. S. (2017). How attachment gave rise to culture. In H. Keller \& K. A. Bard, (Eds.), The cultural nature of attachment: Contextualizing relationships and development (pp. 273-299). Strüngmann Forum Reports, vol. 22, Series Ed. J. Lupp. Cambridge, MA: MIT Press.

Chisholm, J. S., Coall, D. A., \& Atkinson, L. (2016). Mother-infant cultural group selection. Behavioral \& Brain Sciences, 39, e35.

Coall, D. A., \& Hertwig, R. (2010). Grandparental investment: Past, present and future. Behavioral and Brain Sciences, 33, 1-59.

Coall, D. A., \& Hertwig, R. (2011). Grandparental investment: A relic of the past or a resource for the future? Current Directions in Psychological Science, 20, 93-98.

Coall, D. A., Hilbrand, S., \& Hertwig, R. (2014). Predictors of grandparental investment decisions in contemporary Europe: Biological relatedness and beyond. PLoS one, 9(1), e84082.

Coall, D. A., Hilbrand, S., Sear, R., \& Hertwig, R. (2016). A new niche? The theory of grandfather involvement. In A. Buchanan \& A. Rotkirch (Eds.), Grandfathers: Global perspectives (pp. 21-44). Basingstoke: Palgrave Macmillan.

Coall, D. A., Meier, M., Hertwig, R., Wänke, M., \& Höpflinger, F. (2009). Grandparental investment: The influence of reproductive timing and family size. American Journal of Human Biology, 21, 455-463. 
Daly, M., \& Wilson, M. (1980). Discriminative parental solicitude: A biological perspective. Journal of Marriage and the Family, 42, 277-288.

Danielsbacka, M., Tanskanen, A. O., Coall, D. A., \& Jokela, M. (2017). Does grandparental investment improve health and well-being of older Europeans? (Working Papers on Social and Economic Issues 11/2017). Turku: Turku Center for Welfare Research.

Di Gessa, G., Glaser, K., \& Tinker, A. (2016a). The health impact of intensive and nonintensive grandchild care in Europe: New evidence from SHARE. Journals of Gerontology Series B: Psychological Sciences and Social Sciences, 71, 867-879.

Di Gessa, G., Glaser, K., \& Tinker, A. (2016b). The impact of caring for grandchildren on the health of grandparents in Europe: A lifecourse approach. Social Science \& Medicine, 152, 166-175.

Dubas, J. S. (2001). How gender moderates the grandparent-grandchild relationship: A comparison of kin-keeper and kin-selector theories. Journal of Family Issues, 22, 478-492.

Eisenberg, A. R. (1988). Grandchildren's perspectives on relationships with grandparents: The influence of gender across generations. Sex Roles, 19, 205-217.

Euler, H. A., \& Weitzel, B. (1996). Discriminative grandparental solicitude as reproductive strategy. Human Nature, 7, 39-59.

Friedman, D., Hechter, M., \& Kreager, D. (2008). A theory of the value of grandchildren. Rationality and Society, 20, 31-63.

Gibson, M. A., \& Mace, R. (2005). Helpful grandmothers in rural Ethiopia: A study of the effect of kin on child survival and growth. Evolution \& Human Behavior, 26, 469-482.

Gray, P. B., \& Brogdon, E. (2017). Do step- and biological grandparents show differences in investment and emotional closeness with their grandchildren? Evolutionary Psychology, 15, 1-9.

Hamilton, W. D. (1964). The genetical evolution of social behaviour (I and II). Journal of Theoretical Biology, 7, 1-52.

Hank, K., \& Buber, I. (2009). Grandparents caring for their grandchildren: Findings from the 2004 Survey of Health, Ageing and Retirement in Europe. Journal of Family Issues, 30, 53-73.

Hank, K., \& Kreyenfeld, M. (2003). A multilevel analysis of child care and women's fertility decisions in western Germany. Journal of Marriage and Family, 65, 584-596.

Harrington Meyer, M., \& Abdul-Malak, Y. (Eds.). (2016). Grandparenting in the United States. London: Routledge.

Hawkes, K., O'Connell, J. F., Blurton Jones, N. G., Alvarez, H., \& Charnov, E. L. (1998). Grandmothering, menopause and the evolution of human life histories. Proceedings of the National Academy of Sciences, 95, 1336-1339.

Hawkes, K., O'Connell, J. F., \& Blurton Jones, N. G. (1997). Hadza women's time allocation, offspring provisioning, and the evolution of long postmenopausal life spans. Current Anthropology, 38, 551-577.

HayslipJrB., Fruhauf, C. A., \& Dolbin-MacNab, M. L. (2017). Grandparents raising grandchildren: What have we learned over the past decade? The Gerontologist 57, 1196-1196. Advance online publication. doi:10.1093/geront/gnx124.

Hertwig, R., Davis, J. N., \& Sulloway, F. J. (2002). Parental investment: How an equity motive can produce inequality. Psychological Bulletin, 128, 728-745.

Hilbrand, S., Coall, D. A., Gerstorf, D., \& Hertwig, R. (2017). Caregiving within and beyond the family is associated with lower mortality for the caregiver: A prospective study. Evolution and Human Behavior, 38, 397-403.

Hilbrand, S., Coall, D. A., Meyer, A. H., Gerstorf, D., \& Hertwig, R. (2017). A prospective study of associations among helping, health, and longevity. Social Science \& Medicine, 187, 109-117.

Hooper, P. L., Gurven, M., Winking, J., \& Kaplan, H. S. (2015). Inclusive fitness and differential productivity across the lifespan determine intergenerational transfers in a small-scale human society. Proceedings of the Royal Society B: Biological Sciences, 282, 20142808.

Hrdy, S. B. (1999). Mother nature: Maternal instincts and the shaping of the species. London: Chatto and Windus.

Hrdy, S. B. (2009). Mothers and others: The evolutionary origins of mutual understanding. Cambridge, MA: Harvard University Press. 
Huber, B. R., \& Breedlove, W. L. (2007). Evolutionary theory, kinship, and childbirth in cross-cultural perspective. Cross-Cultural Research, 41, 196-219.

Huber, S., Zahourek, P., \& Fieder, M. (2017). Living with own or husband's mother in the household is associated with lower number of children: A cross-cultural analysis. Royal Society Open Science, 4, 170544.

Hughes, M. E., Waite, L. J., LaPierre, T. A., \& Luo, Y. (2007). All in the family: The impact of caring for grandchildren on grandparents' health. Journal of Gerontology: Social Sciences, 62B, S108-S119.

Ivey, P. K. (2000). Cooperative reproduction in Ituri forest hunter-gatherers: Who cares for Efe infants? Current Anthropology, 41, 856-866.

Kanji, S. (2017). Grandparent care: A key factor in mothers' labour force participation in the UK. Journal of Social Policy 18, 1-20.

Kaptijn, R., Thomese, F., Liefbroer, A. C., \& Silverstein, M. (2013). Testing evolutionary theories of discriminative grandparental investment. Journal of Biosocial Science, 45, 289-310.

Kennedy, G. (1990). College students' expectations of grandparent and grandchild role behaviors. The Gerontologist, 30, 43-48.

Kim, P. S., McQueen, J. S., Coxworth, J. E., \& Hawkes, K. (2014). Grandmothering drives the evolution of longevity in a probabilistic model. Journal of Theoretical Biology, 353, 84e94.

Kramer, K. L. (2002). Variation in juvenile dependence: Helping behavior among Maya children. Human Nature, 13, 299-325.

Kurzban, R., Burton-Chellew, M. N., \& West, S. A. (2015). The evolution of altruism in humans. Annual Review of Psychology, 66, 575-599.

Laferrère, A., \& Wolff, F. C. (2006). Microeconomic models of family transfers. In S. C. Kolm \& J. M. Ythier (Eds.), Handbook of the economics of giving, altruism and reciprocity (Vol. 2, pp. 889-969). Amsterdam: Elsevier.

Lahdenperä, M., Lummaa, V., \& Russell, A. F. (2011). Selection on male longevity in a monogamous human population: Late-life survival brings no additional grandchildren. Journal of Evolutionary Biology, 24, 1053-1063.

Lahdenperä, M., Russell, A. F., \& Lummaa, V. (2007). Selection for long lifespan in men: Benefits of grandfathering? Proceedings of the Royal Society B: Biological Sciences, 274, 2437-2444.

Laland, K. N., Sterelny, K., Odling-Smee, J., Hoppitt, W., \& Uller, T. (2011). Cause and effect in biology revisited: Is Mayr's proximate-ultimate dichotomy still useful? Science, 334, 1512-1516.

Mangen, D. J., Bengtson, V. L., \& LandryJr, P. H. (Eds.). (1988). The measurement of intergenerational relations. Beverly Hills, CA: Sage.

Marks, G. N. (2006). Family size, family type and student achievement: Cross-national differences and the role of socioeconomic and school factors. Journal of Comparative Family Studies, 37, 1-24.

Mayr, E. (1961). Cause and effect in biology. Science, 134, 1501-1506.

Michalski, R. L. (2010). Measures of grandparental investment as a limiting factor in theoretical and empirical advancement. Behavioral and Brain Sciences, 33, 32-33.

Oyserman, D., Radin, N., \& Benn, R. (1993). Dynamics in a three-generational family: Teens, grandparents, and babies. Developmental Psychology, 29, 564-572.

Pashos, A. (2000). Does parental uncertainty explain discriminative grandparental solicitude? A crosscultural study in Greece and Germany. Evolution and Human Behavior, 21, 97-109.

Pashos, A., Schwarz, S., \& Björklund, D. F. (2016). Kin investment by step-grandparents - more than expected. Evolutionary Psychology, 14, 1-13.

Perry, G., \& Daly, M. (2017). A model explaining the matrilateral bias in alloparental investment. Proceedings of the National Academy of Sciences, 114, 9290-9295.

Pittman, L. D. (2007). Grandmothers' involvement among young adolescents growing up in poverty. Journal of Research on Adolescence, 17(1), 89-116.

Pollet, T. V., Nelissen, M., \& Nettle, D. (2009). Lineage based differences in grandparental investment: Evidence from a large British cohort study. Journal of Biosocial Science, 41, 355-379.

Pronzato, C. (2017). Fertility decisions and alternative types of childcare. IZA World of Labor, 382. doi:10.15185/izawol.382.

Roberto, K. A., Allen, K. R., \& Blieszner, R. (2001). Grandfathers' perceptions and expectations of relationships with their adult grandchildren. Journal of Family Issues, 22, 407-426. 
Rossi, A. S., \& Rossi, P. H. (1990). Of human bonding: Parent-child relations across the life course. Hawthorne, NY: Aldine de Gruyter.

Rotkirch, A., Lyons, M., David-Barrett, T., \& Jokela, M. (2014). Gratitude for help among friends and siblings. Evolutionary Psychology, 12, 673-686.

Ruiz, S. A., \& Silverstein, M. (2007). Relationships with grandparents and the emotional well-being of late adolescent and young adult grandchildren. Journal of Social Issues, 63, 793-808.

Rutter, M. (2009). Epidemiological methods to tackle causal questions. International Journal of Epidemiology, 38, 3-6.

Schaffnit, S. B., \& Sear, R. (2017). Support for new mothers and fertility in the United Kingdom: Not all support is equal in the decision to have a second child. Population Studies, 1, 17.

Sear, R. (2016). Beyond the nuclear family: An evolutionary perspective on parenting. Current Opinion in Psychology, 7, 98-103.

Sear, R., \& Coall, D. A. (2011). How much does family matter? Cooperative breeding and the demographic transition. Population and Development Review, 37(Suppl.), 81-112.

Sear, R., \& Mace, R. (2008). Who keeps children alive? A review of the effects of kin on child survival. Evolution and Human Behavior, 29, 1-18.

Silverstein, M., \& Long, J. D. (1998). Trajectories of grandparents' perceived solidarity with adult grandchildren: A growth curve analysis over 23 years. Journal of Marriage and the Family, 60, 912-923.

Smith, M. S. (1987). Evolution and developmental psychology: Toward a sociobiology of human development. In C. Crawford, M. Smith, \& D. Krebs (Eds.), Sociobiology and psychology: Ideas, issues and applications (pp. 225-252). Hillsdale, NJ: Lawrence Erlbaum.

Smith, G. C., Strieder, F., Greenberg, P., HayslipJrB., \& Montoro-Rodriguez, J. (2016). Patterns of enrollment and engagement of custodial grandmothers in a randomized clinical trial of psychoeducational interventions. Family Relations, 65, 369-386.

Snopkowski, K., \& Sear, R. (2015). Grandparental help in Indonesia is directed preferentially towards needier descendants: A potential confounder when exploring grandparental influences on child health. Social Science \& Medicine, 128, 105-114.

Snopkowski, K., \& Sear, R. (2016). Does grandparental help mediate the relationship between kin presence and fertility? Demographic Research, 34, 467-498.

St George, J. M., \& Fletcher, R. J. (2014). Men's experiences of grandfatherhood: A welcome surprise. International Journal of Aging and Human Development, 78(4), 351-378.

Strassmann, B. I., \& Garrard, W. M. (2011). Alternatives to the grandmother hypothesis. Human Nature, $22,201-222$.

Suitor, J. J., Sechrist, J., Plikuhn, M., Pardo, S. T., \& Pillemer, K. (2008). Within-family differences in parent-child relations across the life course. Current Directions in Psychological Science, 17, 334338.

Szinovacz, M. E. (1998a). Grandparents today: A demographic profile. The Gerontologist, 38, 37-52.

Szinovacz, M. E. (1998b). Research on grandparenting: Needed refinements in concepts, theories, and methods. In M. E. Szinovacz (Ed.), Handbook on grandparenthood (pp. 257-288). Westport, CT: Greenwood Press.

Szydlik, M. (2008). Intergenerational solidarity and conflict. Journal of Comparative Family Studies, 39, 97-114.

Tanskanen, A. O., Danielsbacka, M., \& Rotkirch, A. (2014). Multi-partner fertility is associated with lower grandparental investment from in-laws in Finland. Advances in Life Course Research, 22, $41-48$.

Taylor, M. F., Marquis, R., Batten, R., \& Coall, D. A. (2016). Understanding the mental health travails of custodial grandparents. Occupational Therapy in Mental Health, 32, 259-280.

Thomese, F., \& Liefbroer, A. C. (2013). Child care and child births: The role of grandparents in the Netherlands. Journal of Marriage and Family, 75(2), 403-421.

Tinsley, B. J., \& Parke, R. D. (1987). Grandparents as interactive and social support agents for families with young infants. International Journal of Aging and Human Development, 25, 259-277.

Tran, U. S., Fisher, M. L., \& Voracek, M. (2009). Spousal age differences and sex differences in life expectancy are confounders of matrilateral biases in kin investment. Basic and Applied Social Psychology, 31, 295-303. 
Trivers, R. L. (1971). The evolution of reciprocal altruism. The Quarterly Review of Biology, 46, 35-57. Uhlenberg, P., \& Hammill, B. G. (1998). Frequency of grandparental contact with grandchild sets: Six factors that make a difference. The Gerontologist, 38, 276-285.

Williams, G. C. (1957). Pleiotropy, natural selection, and the evolution of senescence. Evolution, 11, 398-411. 